\title{
Middle ear myxoma: a diagnostic dilemma and its management, a case report Santanu Dutta ${ }^{a}$, Prasanta K. Gure ${ }^{b}$, Sudipta Pal ${ }^{c}$, Somnath Saha ${ }^{d}$
}

${ }^{a}$ Department of ENT, Head and Neck Surgery, R. G. Kar Medical College and Hospital, ${ }^{b}$ Department of ENT, Head and Neck Surgery, North Bengal Medical College Hospital, Siliguri, 'Department of ENT, Head and Neck Surgery, National Medical College and Hospital,

${ }^{\mathrm{d} D e p a r t m e n t}$ of ENT, Head and Neck Surgery, NRS Medical College and Hospital, Kolkata, India

Correspondence to Sudipta Pal, MS, 223, Jhilpark (Lane 3), Mankundu, Hooghly 712139 , West Bengal, India Tel: +91905 1757391. E-mail: drsudiptapal@gmail.com

Received 27 July 2015

Accepted 3 May 2016

The Egyptian Journal of Otolaryngology 2018, 34:351-354
The aim of this study was to present a rare case report of myxoma of the mastoid cleft/temporal bone with intracranial extension and its management and follow-up. A 13-year-old girl presented with discharge from the right ear with gradually progressive hearing loss for the last 4-5 years and facial palsy of grade III on the right side for the last 4-5 months. She was diagnosed as having chronic otitis media, squamosal type, and underwent canal wall down mastoidectomy on the same ear 6 months back. On examination, an aural polyp occupying the whole of the mastoid cavity along with mucopurulent discharge and lower motor neuron facial palsy were seen on the right side. high resolution ct scan (HRCT) of the temporal bone showed a soft tissue mass occupying the whole of the mastoid cavity breaching bony confinements, extending up to the posterior fossa, extradurally, and engulfing the facial nerve. The patient underwent reexploration of the right mastoid cavity under general anaesthesia and a soft jelly-like substance was removed from whole of the mastoid cavity, extending anteriorly up to the Eustachian tube, inferiorly up to the jugular bulb, posteriorly up to the retrosigmoid cells, superiorly up to the tegmen plate, extending medially intracranially up to the posterior fossa dura through Trautmann's triangle and engulfing the facial nerve from the first genu to the stylomastoid foramen. Facial nerve decompression was performed along with disease clearance and wide conchomeatoplasty. The patient developed grade IV facial palsy postoperatively. The histopathology report of the dissected jelly-like soft tissue revealed myxoma. The patient is at present under regular follow-up and there is no recurrence after 6 months, although facial palsy is still persisting as grade IV. Myxoma of the temporal bone or the mastoid cleft is a rare entity. Complete surgical excision is the treatment of choice in this case, although recurrence is very common. The clinical presentation, management and outcome of this tumour are discussed in view of available literature.

\section{Keywords:}

facial nerve paralysis, histopathology, myxoma, surgical excision, temporal bone

Egypt J Otolaryngol 34:351-354

(C) 2018 The Egyptian Journal of Otolaryngology

$1012-5574$

\section{Introduction}

Myxoma, the name coined by Virchow, in 1871, is a rare tumour, which according to him had a similar appearance to the mucinous tissue of the umbilical cord [1]. Primary myxomas of the temporal bone are very rare tumours. These benign tumours can grow into locally aggressive expansile masses, resulting in hearing loss, facial paralysis, dural invasion and mass effect on the adjacent brain parenchyma [2]. Very often, these tumours resemble and are misdiagnosed as squamosal type of chronic otitis media or cholesteatoma. Intracranial extension, although extremely rare, may mimic a case of cholesteatoma with complication. Radical surgery with wide margins is the treatment of choice, although these tumours have a tendency to recur [3]. Here, we present and discuss the case of a young girl who was diagnosed as having myxoma of the temporal bone with intracranial extension and its management.

\section{Case report}

S.N., a 13-year-old girl, presented to the ENT OPD of a tertiary care hospital of Kolkata with complaints of discharge and hearing loss in the right ear for the last $4-5$ years and deviation of the angle of mouth to the left side for the last 4-5 months. She was diagnosed as having squamosal type of chronic otitis media and underwent canal wall down mastoidectomy on the right side 6 months back. On examination, a pinkish mass covered with mucopurulent discharge was found to be occluding the whole right mastoid cavity, and after cleaning the discharge it was found to be a pinkish polypoidal mass, soft-to-firm in consistency, not painful or bleeding to touch, free from meatoplasty

\footnotetext{
This is an open access journal, and articles are distributed under the terms of the Creative Commons Attribution-NonCommercial-ShareAlike 4.0 License, which allows others to remix, tweak, and build upon the work non-commercially, as long as appropriate credit is given and the new creations are licensed under the identical terms.
} 
opening all around but occluding it and obscuring the view of mastoid cavity. The patient also had a rightsided lower motor neuron facial palsy of House-Brackmann grade III, which was not present immediately after mastoidectomy 6 months back, but developed later on and was progressive in nature for the last 4-5 months. A tuning fork test with $512 \mathrm{~Hz}$ showed that Rinne was negative on the right side and Weber was lateralized to the right ear. Puretone audiometry showed $45-50 \mathrm{~dB}$ hearing loss of conductive type in the right ear, and HRCT of the temporal bone ( $1 \mathrm{~mm}$ axial and coronal cuts) showed a poorly enhancing soft tissue mass occupying the whole of the mastoid and middle ear cavity with destruction of the sinus plate, middle ear ossicles, the lateral and inferior wall of right mastoid and facial canal, extending up to the posterior fossa, extradurally; however, the inner ear structures, internal auditory canals, and bilateral cerebello pontine (CP) angles were found to be normal.

The right mastoid was re-explored under general anaesthesia and a soft jelly-like substance was removed from whole of the mastoid cavity, extending anteriorly up to the Eustachian tube, inferiorly up to the jugular bulb, posteriorly up to the retrosigmoid cells, superiorly up to the tegmen plate, not breaching it, but extending medially intracranially up to the posterior fossa dura through Trautmann's triangle and engulfing the facial nerve from the first genu to the stylomastoid foramen. Facial nerve decompression was performed along with disease clearance from the middle ear cleft and the posterior fossa through Trautmann's triangle, and a wide well-saucerized cavity along with a wider conchomeatoplasty was performed. The patient developed grade IV facial palsy postoperatively.

Histopathological examination report of the dissected tissues came as a lesion composed of stellate or spindleshaped cells lying in a loose-textured myxoid, wellvascularized stroma. The tumour cells did not show significant nuclear pleomorphism or mitotic activity. Epithelial inclusion cysts and spicules of dead bone were present. No epithelioid granuloma or evidence of malignancy was noted. The picture pointed towards the diagnosis of myxoma. The patient is at present under regular follow-up and there is no recurrence after 6 months, although facial palsy is still persisting as grade IV (Figs 1-5).

\section{Discussion}

\section{Myxoma}

Myxomas are rare benign tumours arising from the mesenchymal tissues throughout the body [4], and may be seen in the skin, subcutaneous tissue, skeletal muscles, heart and genitourinary system [3]. It occurs most frequently in the heart and jaw bone, less frequently in the temporal bone mastoidium and rarely in the cranial base of the brain [1]. Primary myxoma of the head and neck region occurs mostly in the maxilla and mandible, owing to the fact that it arises from tooth germ cells [5], but myxoma in the temporal bone is quite rare and involvement of the skull base with intracranial extension is extremely rare [4]. To date, there are less than 15 cases of temporal bone myxoma reported worldwide [3].

\section{Figure 1}

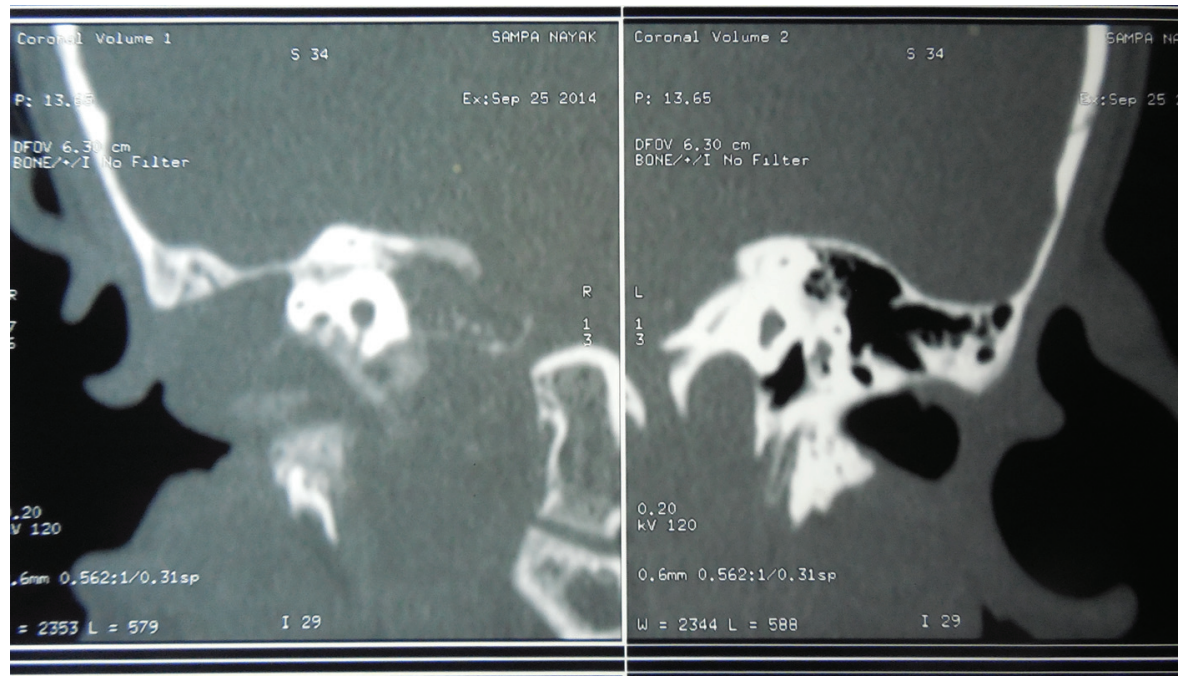

HRCT of the temporal bone coronal cuts showing tumour with extensions. 
Figure 2

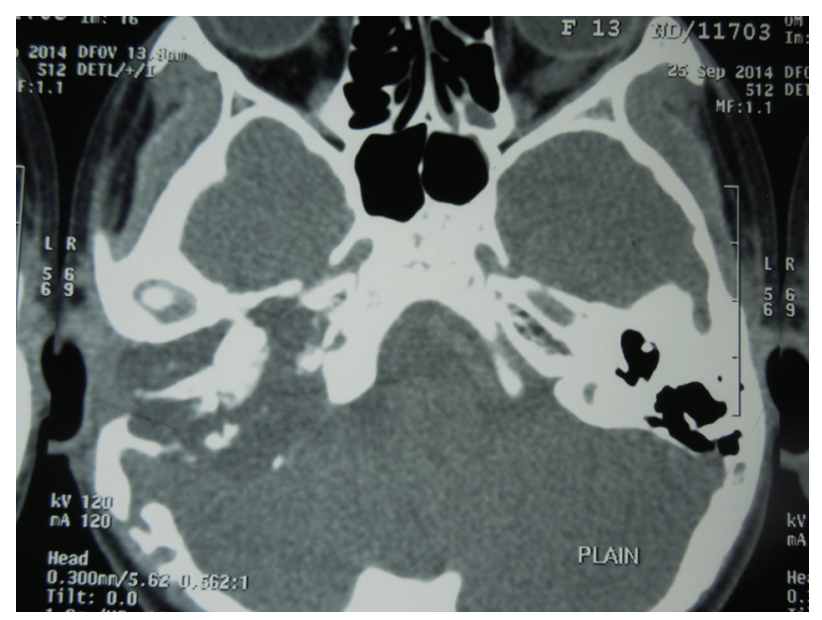

HRCT of the temporal bone axial cuts showing tumour with extensions.

Figure 3

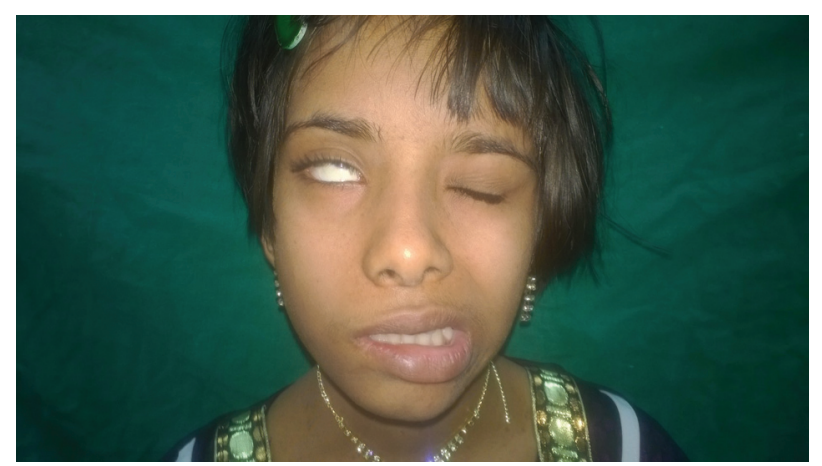

Postoperative facial palsy.

Myxomas may be classified into five types: cutaneous (superficial angiomyxoma), intramuscular, juxtaarticular, nerve sheath and aggressive angiomyxoma $[6,7]$. According to Kleinsasser [8], primitive mesenchyme filling the middle ear space in embryo and in newborn may give rise to temporal bone myxoma.

Myxomas of the temporal bone are very difficult to diagnose and often misdiagnosed as their presentation mimics chronic otitis media. Patients usually present with recurrent otitis media, facial paralysis, mass in external auditory canal or retroauricular mass. These tumours, although benign and slow-growing, are locally aggressive and infiltrative in nature and can cause significant destruction of the adjacent tissues. If left untreated or misdiagnosed, locally aggressive expansile mass can cause dural invasion and mass effect on the adjacent brain parenchyma [2,3]. These findings often mislead the clinician to diagnose it improperly as cholesteatoma or squamosal variety of chronic otitis media.
Figure 4

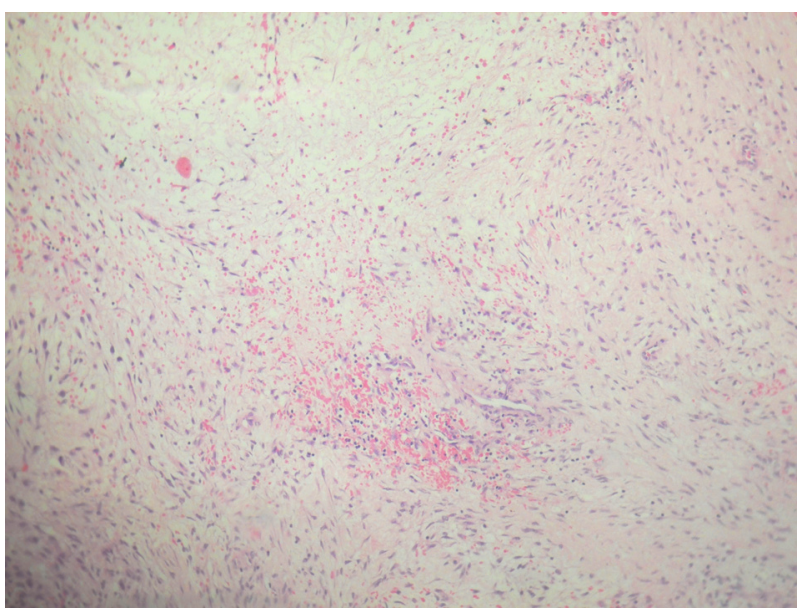

Histopathological picture of myxoma ( $\times 10$ magnification).

Figure 5

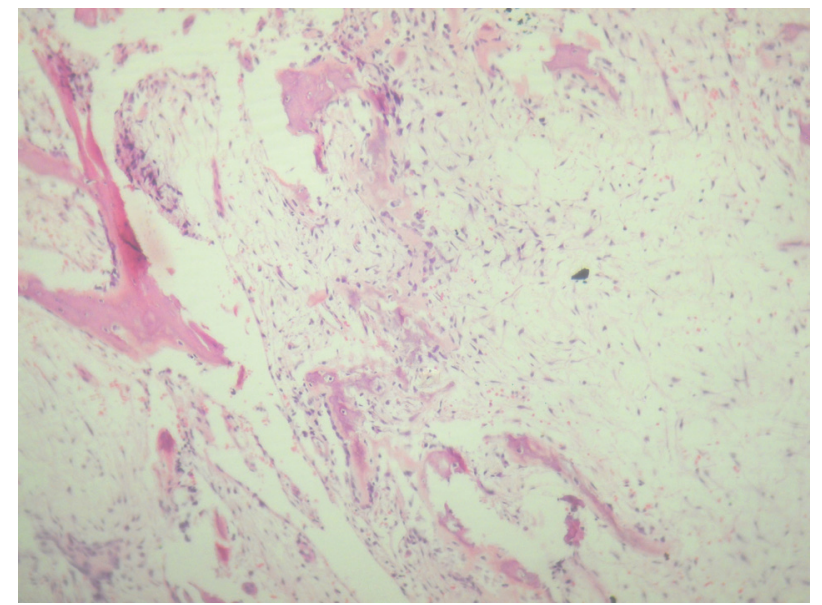

Histopathological picture of myxoma ( $\times 40$ magnification).

Acute peripheral facial paralysis may be rarely due to two rare middle ear tumours: myxoma and carcinoid tumour [9]. One should consider this rare cause in differential diagnosis. Patients remain asymptomatic unless this slow-growing tumour irritates or involves facial nerve or the vestibular organ, and facial palsy may be the presenting sign [10]. A case of myxoma of the mastoid with initial facial spasm followed by palsy of the nerve had been reported long before in the year 1978 , and after removal of the tumour the nerve was reconstructed from the second genu to the stylomastoid foramen [11].

Radiological evaluation is commonly carried out using HRCT of the temporal bone, plain and contrast enhanced, $1 \mathrm{~mm}$ axial and coronal cuts, which shows enhancing mass lesion in the temporal bone with infiltration into surrounding structures [12]. MRI may be helpful, particularly in myxomas of the 
cranial base of the brain and tumours located at the middle fossa, parasellar and jugular region, which shows characteristic calcification [1]. Pure-tone audiometry usually reveals conductive hearing loss but may be normal at times. Laboratory tests of vestibular functions may be positive if the tumour invades the inner ear [12].

Myxomas are very difficult to diagnose histopathologically. As per Stout's [13] definition of a true myxoma, it is a true mesenchymal neoplasm if it consists of undifferentiated stellate cells in a loose myxoid stroma and its diagnosis excludes the presence of lipoblast, myoblast, chondroblast or other elements. Histologically, it presents as a 'myxoid' matrix that is rich in acid mucopolysaccharides [10] and often confused with other tumours that can present mucoid degeneration [14].

Thus, diagnosis of myxoma requires a high degree of suspicion and detailed histopathological examination. Differential diagnosis commonly includes fibrous dysplasia, chondromyxoid fibroma, fibrosarcoma, chondrosarcoma, schwannoma, giant cell granuloma, chordoma, haemangioma of the bone, haemangiopericytoma, metastatic tumours of the skull, meningioma and other neoplasms of the dura and skull base in this location $[3,4]$.

Management is mainly surgical with wide local margin, although en-bloc excision with wide margin is not always possible because of ill-defined margin of the tumour and complex anatomy of the temporal bone [15]. Radical surgery should be planned according to the facial nerve and inner ear involvement. It is wise to operate thoroughly without sacrificing vital structures and the drilling should be adequate. Despite radical surgery, the tumour shows local recurrence and at times it is very difficult to remove the tumour completely because of its gelatinous consistency [16]. Bony facial canal may or may not be destroyed and the management of facial nerve largely depends upon peroperative findings $[3,10]$.

Treatment results of myxomas are seldom encouraging; the goal of complete surgical resection is rarely achieved and these are very notorious for local recurrence. The outcome of radiotherapy is not very successful [1].
Hence, regular and strict follow-up is mandatory, particularly in young patients, both clinically and radiologically [3].

\section{Conclusion}

Primary myxoma of the temporal bone is a very rare benign mesenchymal tumour that is locally aggressive. It is very difficult to diagnose clinically, radiologically and histopathologically. A high index of suspicion is required for early detection of this rare tumour, which will facilitate early surgical removal. Treatment of choice is radical surgery but it has a tendency to recur. Regular follow-up after complete surgical excision is mandatory.

\section{Acknowledgements \\ Conflicts of interest}

There are no conflicts of interest.

\section{References}

1 Zhang L, Zhang M, Zhang J, Luo L, Xu Z, Li G, et al. Myxoma of the cranial base. Surg Neurol 2007;68:S22-S28.

2 Guha-Thakurta N, Deavers M, DeMonte F, Gidley PW. The natural history of primary temporal bone myxoma. Ann Diagn Pathol 2012;16:280-283.

3 Sikka K, Kumar R, Kumar R, Sagar P, Sing L. Myxoma of the temporal bone: a rare neoplasm. Indian J Otol 2011;17:173-175.

4 Oruckaptan HH, Sarac S, Gedikoglu G. Primary intracranial myxoma of the lateral skull base: a rare entity in clinical practice. Turk Neurosurg 2010;20:86-89.

5 White DK, Chen SY, Mohnac AM, Miller AS. Odontogenic myxoma. A clinical and ultrastructural study. J Oral Surg 1975;36:901-907.

6 Weiss SW, Goldbum JR. Benign soft tissue tumors and pseudotumors of miscellaneous type. In: Weiss SW, Goldblum JRs, editors. Soft tissue tumors. 4th ed. St Louis: Mosby; 2001: 1419-1481.

7 Allen PW. Myxoma is not a single entity: a review of the concept. Ann Diagn Pathol 2000;4:99-123.

8 Kleinsasser O. Osteoblastic myxoma of the ear ('otenchymoma'). HNO 1966;14:218-222.

9 Zehlicke T, Punke C, Boltze C, Pau HW. Transient facial palsy in two cases of benign, very rare middle ear tumors (carcinoid tumor and myxoma). Neurologist 2008;14:52-55.

10 Zehlicke T, Punke C, Haase K, Boltze C, Pau HW. Myxoma of the middle ear-a rare cause of facial palsy [in German]. HNO 2008;56:165-168.

11 Neiger M. Myxoma of the mastoid with destruction of the facial nerve [in German]. Laryngol Rhinol Otol (Stuttg) 1978;57:912-913.

12 Hsieh DL, Tseng HM, Young YH. Audiovestibular evolution in a patient undergoing surgical resection of a temporal bone myxoma. Eur Arch Otorhinolaryngol 2006;263:614-617.

13 Stout AP. Myxoma: the tumor of primitive mesenchyme. Ann Surg 1948;127:706-719.

14 Maiuri F, Corriero G, Galicchio B, Angrisani P, Bonavolontà G. Myxoma of the skull and orbit. Neurochirurgia (Stuttg) 1988;31:136-138.

15 Windfuhr JP, Schwerdtfeger FP. Myxoma of the lateral skull base: clinical features and management. Laryngoscope 2004;114:249-254.

16 Charabi S, Engel P, Bonding P. Myxoid tumours in the temporal bone. J Laryngol Otol 1989;103:1206-1209. 